\title{
13. The need to design collaboration: improving the effectiveness of commissioning with design thinking
}

Michael Mintrom and Madeline Thomas

\section{INTRODUCTION}

Public policies and programs are intended to improve the lives of citizens. When they are well-designed and well-implemented, policies and programs can do much to generate valued economic and social outcomes. Considerable efforts are currently being made to utilize evidence, conduct experiments, and use program monitoring to increase the likelihood that policies and programs will generate intended effects (Mintrom and Thomas 2018). Here, we explore the neglected connection between design thinking and effective commissioning of public services.

Governments commission the delivery of public services with the expectation it will lead to better services and more efficient resource use. Commissioning refers to a set of activities from needs assessment, to contract specification, to service delivery, through to outcome evaluation (Dickinson 2014). Commissioning of services delivered by third parties is growing in prominence and its success depends on collaboration. However, collaboration alone is never guaranteed to generate successful outcomes. Government agencies need to work harder during the creation of collaborations to increase the odds of commissioning being effective (Mintrom and Thomas 2018). We contend that greater use of design thinking can improve analytical governance capacities. Specifically, it can harness the knowledge of local contexts to improve collaborative efforts in service delivery. In turn, it can increase the odds that public investments will generate anticipated social and economic outcomes.

In what follows, we first discuss the potential benefits of collaboration and explore factors that may hinder effective collaboration in the realm of public service provision. We then note evidence on how differences in the implementation and management of public services can generate strikingly different local outcomes. From here, we provide a general argument for how design 
thinking strategies can promote effective commissioning. Next, we use the illustrative case of charter schooling to show how knowledge of local contexts can improve commissioning. Drawing insights from this case, we conclude by arguing that improved client engagement and design thinking offer promising ways to improve commissioning and increase the odds of generating positive social and economic outcomes.

\section{THE PROMISE OF COLLABORATION}

There is no single definition of collaboration, but generally it is agreed that it is a series of interrelated, mutually beneficial activities undertaken by partners or stakeholders to address shared problems and achieve common goals (Mattessich, Murray-Close and Monsey 2001; Melaville, Blank and Asayesh 1993). Collaboration may be between two or more government agencies (public-public) or between government agencies and private firms or non-profit organizations (public-private). Collaboration may also be referred to as 'whole-of-government', 'joined up government', 'cross-cutting', or 'integrated government'. Regardless of the term used, the core features of collaboration involve organizations: (1) working across traditional boundaries; (2) developing an integrated approach to a complex issue; and (3) sharing responsibility for an outcome, including the risks and rewards. Collaboration came to prominence in the public service in 1997 when the British New Labour Government promoted the concept. It has since been taken up in many countries throughout the world as a method for solving complex public challenges.

Collaborative advantage and collaborative inertia are two concepts which represent the possible success and failure of collaboration. When there is collaborative advantage something has been achieved that could not have been achieved by one organization alone. Meanwhile, collaborative inertia depicts the case where the achievement from a collaboration is negligible and slow in coming (Huxham and Vangen 2008).

John Wanna (2008) highlights some key benefits of collaboration. First, collaboration can lead to better policy development and service delivery because it allows all relevant stakeholders to combine their skills and expertise leading to better resolutions of policy issues. Collaboration can bring together multiple perspectives and lead to the development of informed policy solutions which may otherwise not have been reached by one agency alone. Second, by prompting engagement with relevant stakeholders early in the development of solutions to policy issues, collaboration is likely to lead to greater support for the policy implementation across government and the community. Third, collaboration contributes to mutual learning and capacity building across organizations through the development of relationships and networks. 


\section{Collaboration in Action}

The benefits of collaboration are demonstrated in the New Zealand case of Schooling Effectiveness in Mangere and Otara (SEMO) (Eppel et al. 2008). In this instance, the aim was to achieve better educational outcomes for hundreds of predominately Maori and Pacifika children in South Auckland. In 1996, the Education Review Office concluded that fifty schools in South Auckland were failing to help their students learn at an acceptable level. The students were from some of the most disadvantaged homes in New Zealand. These schools became part of the SEMO project. Originally, there was not a detailed plan, only the idea that children in South Auckland were entitled to schooling as good as anywhere else in the country. Parents were angry, either because their children's schools were being shamed, or because their children were not learning appropriately. Principals and teachers blamed the government for a lack of resources.

The portfolio manager in the Ministry of Education was not content to follow established approaches and allocate additional resources without a plan for how the quality of education the children received could be improved. Experts in the Ministry of Education lacked confidence that they understood the problem enough to design a solution without local context knowledge. They decided they needed local community knowledge, capability, and involvement.

A key decision was to have expert education observers work alongside school, Ministry, and community actors in a trusted confidant role as external researchers/evaluators. These observers became integral to recording and critiquing the actions of those involved and the results they achieved. The observers assisted those involved as they tried to understand the various dimensions of a complex and entrenched problem, and attempt new ways of doing things. The observers were also able to externally validate success and change.

The Ministry took a new and risky step of inviting the schools to contribute to the job descriptions for two project managers to look after the schooling improvement work in Mangere and Otara. Two experienced and high-performing Auckland principals were appointed as project managers.

These two steps marked the beginning of a new way of working both within the Ministry of Education and between the Ministry and the schools. There were many tensions and challenges with the schools wanting more resources and the Ministry believing that they were not fully utilizing the resources they already had. However, the project managers with their experience and local knowledge were able to build credibility and relationships with the boards, local school communities, and even teachers unions. Additionally, with the help of external observers, student learning improved to meet the national average (Annan 2007; Timperley and Robinson 2001). 
Improving the quality of the education outcomes for South Auckland students required change in how the Ministry of Education worked with internal and external agencies. While it had the resources, the Ministry had insufficient understanding of complex local issues that resulted in school failure, and what exactly was to be done to bring lasting change. In this case, no one organization had all the information and resources to address the complex issues at hand. For the Ministry of Education, it meant doing things differently and gaining local knowledge. For the school boards, it meant holding their principals and staff accountable and learning how to make improvements.

While collaboration can have many benefits, successful or effective collaboration is not always easily achieved and can face many barriers. The nature of collaboration is that it cuts across organizations, which can lead to difficulties in determining who is responsible for what. Furthermore, collaboration can be time-consuming, expensive, and in the end, may not lead to a unanimously supported decision. That can delay implementation. There is also the concept of a collaborative ruse, where collaboration is undertaken for ulterior political motives such as 'selling' decisions made elsewhere or previously undertaken by government departments (Wanna 2008).

People or organizations who do not wish to work together represent possibly the largest barrier to collaboration. Where people perceive that collaboration is a waste of time or money or that it will threaten their organizational identity or their positional power, they will likely resist it. Historical tensions or ideological differences can lead to adversarial relationships which prevent collaboration. Those leading collaborative endeavours should prepare accordingly to address the reasons why people may decline to engage in collaboration (Majumdar 2006).

The key element of effective collaboration is a commitment to mutual understanding, respect, and trust from the organizations involved (Alford and O'Flynn 2012; Majumdar 2006). Collaboration should only be adopted when it is judged that a reasonable level of trust between organizations is already present or could be realistically achieved. Trust is never easy to foster. Careful consideration should be given to whether collaboration is feasible or worthwhile in terms of the value it is expected to generate (Alford and O'Flynn 2012). Those who take the time needed to understand and respect others' values, priorities, and organizational constraints are more likely to evoke more trust. This can encourage more openness about agendas, service needs, and resources. Even if there are inequalities in power, resources, and skills, organizations can collaborate effectively if they discuss real or imagined imbalances at the outset, assess their strengths and weaknesses as related to the project, and determine whom is able to best contribute what (Majumdar 2006).

Collaboration has the potential to successfully address difficult policy problems. When this happens, as with the case of the South Auckland schools, 
peoples' lives are improved. The more people can enjoy good education, good health, and live within the law, more freedoms and opportunities are available to them. The experience of living a good life is impossible to quantify in any simple fashion. Still, everyone benefits when as many people as possible are enabled to live well. Collaboration offers a path towards that outcome.

\section{VARIANCE IN SERVICE PERFORMANCE AND OUTCOMES}

As a general practice, policy design tends to occur far from the places where policy implementation happens. Consequently, policy design is often removed from the gritty environments experienced daily by citizens and service managers as they translate policies into actions. Information relevant to policy design and the promotion of better outcomes does not automatically filter back to the policymakers in ways that can inform their design work (Mintrom and Thomas 2018). These differences between the worlds of policy designers and public managers mean implementation of the same policy can result in starkly different outcomes across organizations (Howlett and Rayner 2007). The strategic choices public managers make and the actions they pursue materially influence policy outcomes (Meier and O'Toole 2001). Given this, those charged with engaging in policy design should be fully aware of the contexts in which policy changes are to be implemented. Often, they are not. Further, there are strong institutional and organizational pressures in local settings that can blunt the intended purposes of public policies.

Reflecting on the education sector, Larry Cuban (1998: 453) claimed that 'schools change reforms as much as reforms change schools'. This observation was not intended to illustrate the deviant nature of schools. Instead, it emphasized that schools are complex organizations embedded in broader institutional settings. To balance policy expectations with the embedded practices and expectations of a range of local stakeholders, decision-makers in these local contexts must often make trade-offs.

At the level of ideals, policy designers typically desire that any given policy will generate uniformly positive outcomes across multiple settings. For example, if a certain level of health care funding is provided to localities based upon population characteristics, then the usual expectation is that such funding should generate similar health outcomes for the populations across those localities. To the extent that such uniform results are not observed, a dilemma emerges for policy designers. Should they insist on the promotion of similar program delivery processes, or should they insist on promotion of similar outcomes? Answers to that question will depend crucially on whether people perceive differences in outcomes to be the product of problems in the general- 
izability of policy or to be the product of problems resulting from differences in local contexts and their implementation processes.

A lot of policy analysis over the past few decades has sought to apply forms of comparative institutional analysis to identify and explain local variations in the effectiveness of public policies. While it is usually challenging to draw strong conclusions for why policy outcomes differ across localities, policymakers frequently desire to improve those outcomes and reduce variations across them. That desire contributes greatly to the diffusion of policy innovations. It also explains the tendency for specific policy approaches to be clustered under popular headings which have their own life cycles. Policy practitioners and policy scholars alike are drawn to discussing problems and solutions using currently popular terminology. None of us are immune from that. The bigger challenge - which transcends policy fads and fashions - is to design public policies that contribute as effectively as possible to the solving of problems for the greatest number of people. Next, we discuss how the application of insight from design thinking can potentially improve service commissioning in ways that lead to broadly improved social outcomes.

\section{DESIGN THINKING AND EFFECTIVE COMMISSIONING}

In the tradition of public policy theory and teaching, design has long been seen as a component of policy development (Howlett 2010; Lynn and Gould 1980; Schneider and Ingram 1997). Policy implementation depends on the design of products and services (Alford 2009; Lipsky 1980; Wilson 1989). Design thinking in industrial settings is concerned with making product developers more aware of the practices and expectations of the consumers of their products (Brown 2009; Brown and Wyatt 2015; Martin 2009). With respect to public policy, many gaps exist between the services governments deliver and what citizens want. To remedy this, good policy should be informed by deep knowledge of the contexts and clients for which that policy is being made. This is crucial for enhancing public value (Moore 1995).

Here, we consider how design thinking might be used to promote the analytical capability of governing actors and, in turn, contribute to more effective commissioning. Public service commissioning reduces the role of the state in the provision of services. Instead, the government becomes an enabler and an overseer that assesses the needs of defined populations and the outcomes achieved through service delivery (Dickinson 2014). Design thinking encourages end-users, policy designers, central departments and line agencies to work in a collaborative and iterative manner (Mintrom and Luetjens 2016). The most important skill for a design thinker is to 'imagine the world from multiple perspectives - those of colleagues, clients, end-users, 
and customers (current and prospective)' (Brown 2008: 87). This is where greater empathy for different perspectives emerges. Design thinking does not start with a presumption of a known answer, or even a well-defined problem. Design thinking is intended to improve understanding of the local context and the practices of agents operating within them. The expectation is that, through this process, insights will be gained into the logics that drive the choices of those contextualized agents. Rather than assume or infer motivations and practices, design thinking encourages observation of practices and grounded interpretations of those practices. Through iterative ethnographic methods, design thinking holds the promise of bridging the common gap between the goals of policymaking and the experiences of citizens as they interact with government services. When appropriately applied, the approach holds the potential to improve the analytical capabilities of governance systems. Likewise, it promises to increase the likelihood of successful collaboration on service delivery. Improvements in collaboration and service delivery represent important margins for promoting better return on the investment of public funding. Often, the very same quantum of resources used to generate mediocre outcomes can - with the benefit of insights generated through design thinking - generate better outcomes, to the benefit of all in society.

Focusing on the lived experiences of citizens and service-users is expected to promote better policymaking. In the best cases, such policies should lead to implementation of programs that enhance public value and represent good return on the investment of public funds (Mintrom and Thomas 2018). Suppose a government had the goal of improving educational processes and outcomes in public schools. A design project intended to inform such an effort would start by seeking to identify regularities across individual behaviour that suggest the need for forms of mechanism design and service delivery that improve upon current ones. Such a project might work through questions of this sort:

- Where are the areas of poorest school performance at present?

- What factors appear to engender poor school outcomes?

- Where is poor schooling most likely to be observed in the coming years?

- How are the teaching strategies of teachers in poorly performing schools different from those of teachers in high performing schools?

- Under what circumstances does poor school performance lead to other problems, such as teen unemployment, substance dependency, or criminal activity?

- What do children and parents in poorly performing schools want from school teachers and school leaders? 
- What are some success stories of interventions that have assisted schools to turn around their performance and generate good outcomes for their students?

This set of questions specific to improving educational processes and outcomes could be readily adapted to prompt design thinking across other areas where some form of policy change is considered necessary to improve social outcomes.

The application of design thinking - tapping the knowledge of targeted individuals, creating opportunities for significant public engagement of diverse perspectives, and prototyping interventions - can be pursued through a range of techniques. Here, we briefly introduce five: (1) Environmental Scanning, (2) Participant Observation, (3) Open-to-Learning Conversations; (4) Mapping; and (5) Sensemaking. All could usefully inform commissioning work with the purpose of securing better social outcomes.

\section{Environmental Scanning}

This strategy explores present behaviours of individuals and groups in given localities and the outcomes resulting from those behaviours. It also seeks to identify trends that may influence future outcomes (Fahey and King 1977). It requires taking stock of a particular situation and scanning for new inputs, materials, influences and technologies applied in other fields that may be relevant (Etzioni 1986). Used appropriately, it creates an evidence-based method of gathering, synthesizing, and interpreting information which can shift the attention of an organization toward new opportunity areas, threats, and potential blind spots. Environmental scanning can assist with commissioning, by improving knowledge of strategies that work well across many contexts.

\section{Participant Observation}

Observation refers to the ability to notice significant and seemingly insignificant details to gather information. In developing a framework for understanding information processing in problem-solving tasks, Newell and Simon (1972) emphasized the importance of task effects on decision behaviour. While environmental scanning facilitates the broad exploration of an issue, observation requires engaging with people encountering specific problems. It can access tacit, otherwise difficult-to-capture knowledge from subjects (Polanyi 1966). Design thinking applies observation to understand people and their behaviour in the context of their lives. This can involve observing someone complete a task or engage with a service. The observer accompanies the subject through the steps, and may ask the subject to explain what they are 
doing at each step. Observation is particularly useful for understanding the effect that a policy has on marginalized groups of people. In this context - as in many others - empathy is critical to effective observation (Wagenaar 2014). Observation can assist with commissioning by improving knowledge of local settings and any specific policy requirements emerging within them.

\section{Open to Learning Conversations}

There is a common tendency among service-producing organizations to limit choices for clients and make incremental adjustments. Problems are addressed using standard operating procedures that attempt to maintain predefined notions of order. This is true in all sectors of society, including the public sector. Chris Argyris $(1982,1991)$ explored this phenomenon in the context of single- and double-loop learning. Single-loop learning suggests that when something goes wrong, people seek alternate strategies that will work within present constrained choices. In double-loop learning, the alternate response is to question the existing choice set. Double-loop learning, or divergent thinking, is the route to innovation. To achieve divergent thinking, it is important to have a diverse group of people involved in the process. Open to learning conversations encourage divergent thinking (Martin 2009; Neumeier 2009). Such conversations are less about analyzing existing options and more about the creation of new options and questioning the fundamental basis of existing structures. Open to learning conversations can assist with commissioning. Specifically, they can allow policy designers, service managers, and clients to understand each other's concerns and ultimately lead to more productive interactions.

\section{Mapping}

Mapping has long been used in policymaking to explore the links between mechanism design and implementation (Elmore 1979). A concept map can be used to develop a conceptual framework to guide evaluation or planning (Trochim 1989). Such a framework can organize some of what has been learned during previous phases of design processes. Mapping allows the designer to visualize how things connect, and spot emerging patterns. This can be done by putting one idea, or user, at the centre and then mapping how the other ideas and insights play off it. Mapping can be used to systematically visualize human experiences and think about steps or 'touchpoints' of a process. Journey mapping communicates the user experience from beginning to end and offers broader, sophisticated and holistic knowledge of user experience. It can reveal problems and help suggest alternate pathways forward. This can be a very powerful antidote to complacency and a good way to challenge 
conventional thinking. There are many ways this can be done. For example, if a hospital wanted to improve patient experiences, it would be useful to know the steps involved between when the patient leaves their house, enters the hospital, speaks with the triage nurse, and speaks with additional people or hospital staff. Visually mapping experiences such as these can help identify areas where services or processes can be eliminated, streamlined, enhanced or changed (Ben-Tovim et al. 2008; Radnor et al. 2014). Mapping can assist with commissioning by giving policy designers new insights into where current systems work well and where they do not, and where attention to making improvements should be prioritized.

\section{Sensemaking}

Karl Weick (1985) defined sensemaking as an action-oriented process that people automatically go through to integrate experiences into their understanding of the world around them. The sensemaking perspective suggests that in organizational settings much latitude exists in the interpretation of situations and events. Sensemaking requires connections to be forged between seemingly unrelated issues through a process of selective pruning and visual organization. Dialogue is critical to sensemaking. Once data and insights have been externalized - say in the form of post-it notes on a wall - designers can begin the more intellectual task of identifying explicit and implicit relationships, physically drawing out these content-affinities through the process of organization. The designer begins to move content around, physically, placing items that are related next to each other. All of the content is related in some way, but the important connections are frequently those that are multifaceted and complex. Once the groupings begin to emerge, they can be labelled and understood. Sensemaking can assist with commissioning. Like the other techniques discussed here, it encourages policy designers to work with service managers and clients, take cues from conversations, and identify promising strategies for aligning the provision of services with client needs.

\section{HARNESSING LOCAL KNOWLEDGE: AN ILLUSTRATIVE CASE}

The degree to which societies benefit from specific public policies will depend greatly on the care taken to ensure those policies are translated into high quality programs at the local level. To explore this further, we use an illustrative case. The case concerns the efforts of Doug Lemov, an educator who has used opportunities created by the charter schools movement to transform elements of teaching practice. 
Charter schools are publicly funded but they enjoy a high degree of autonomy from traditional school district systems of control and accountability. By allowing the creation of charter schools, states in the United States have facilitated a form of marketization in the provision of public schooling, with the various opportunities and risks that accompany such governance changes (Howlett and Ramesh 2016). The first charter schools opened in Minnesota in 1992 (Mintrom and Vergari 1997). Although they are granted their independence by states, charter schools are given no guaranteed student base. They survive on their ability to attract and retain viable student numbers. Since their inception, charter schools have been expected to be more innovative than traditional public schools. It has also been expected that competition from these schools would pressure traditional public schools to improve their practices. Evidence suggests charter schools have been more open to innovation than traditional public schools. Often, this has involved taking selective practices developed in traditional public schools and combining them to create a more innovative kind of schooling. The extent to which innovative practices in charter schools have filtered back to traditional public schools has remained a difficult question to answer (Mintrom 2001). However, it is clear that differences in the design of governance structures can significantly influence the number and variety of charter schools operating within a jurisdiction (Mintrom 2002).

Uncommon Schools is a non-profit network of over forty public charter schools operating in New York, New Jersey, and Massachusetts. Enrollments at schools in the network currently exceed 12,000. The schools aspire to work effectively with families in low-income communities to prepare their children for college and college graduation. Uncommon Schools won the 2013 Broad Prize for Public Charter Schools for demonstrating 'the most outstanding overall student performance and improvement in the nation in recent years while reducing achievement gaps for low income students and students of color' (Lemov 2015: xxxii).

An unusual amount of knowledge has been shared about Uncommon Schools as the result of the books written on exceptional teaching produced by Doug Lemov. Lemov is a former charter school principal, and a managing director of Uncommon Schools who leads its Teach Like a Champion team. Lemov has made a science out of using educational data to identify top performing teachers and then studying and codifying their instructional methods.

The design thinking approach worked as follows. Using a form of environment scanning, Lemov reviewed school-level results on standardized state tests, like the New York State Assessment Sixth-Grade Math results. For each school, he recorded the percentage of students deemed proficient on the standardized test. Next, he ranked those same schools based on their recorded student poverty rate (judged by the percentage of children eligible to partic- 
ipate in the federally funded free lunch program). Lemov graphed these two indicators.

As expected in data like these, there is a strong negative relationship in schools between rate of student poverty and average levels of student proficiency on standardized state tests. The higher the percentage of students in poverty in a school, the lower the expected percentage of students deemed proficient. However, Lemov's interest lay in schools that recorded high levels of proficiency despite having high levels of student poverty. A handful broke the trend. Consistent with sensemaking practices, Lemov asked: What are teachers doing differently in those schools? Specifically, how did they approach teaching, lesson-planning, and relationship management with students and their families?

Lemov's question led him to visit schools and engage in close observation of teaching practices. He spoke with principals and teachers, and - most importantly - codified the specific, concrete, actionable classroom practices of teachers who attained such outstanding results with their students. Through observation and open to learning conversations, Lemov developed a set of teaching techniques that he then systematically trained teachers in Uncommon Schools to utilize. We might say that through system mapping, Lemov was able to carefully trace the steps from teacher preparation and classroom interactions to student learning and, ultimately, student acquisition of knowledge required to perform effectively in high school and beyond. Following adoption of these teaching techniques, the Uncommon Schools have been generating significant improvements in student outcomes compared to what all the typical social indicators would lead us to predict.

Lemov developed his set of teaching techniques into a book, Teach Like a Champion, first published in 2012. It has been estimated one quarter of the population of teachers in the United States subsequently read the book or were exposed to techniques in it. That is almost 800,000 teachers, across all types of schools - public, independent, private, urban, suburban, rural. The book has been highly influential in many countries around the world, including Brazil, India, and China.

Without doubt, Doug Lemov's innovation actions that were facilitated by the charter school movement have had a major impact on teaching practices well beyond the Uncommon Schools where it all began. Lemov has used design thinking and evidence-based techniques to deploy resources - teachers, students, classrooms - in a fashion that yields high returns on investments, whereas others continue to use the equivalent resources and obtain limited results. Lemov has shown that it is possible to make significant changes in school practices and generate better student outcomes.

The case of Doug Lemov and the Uncommon Schools offers a positive illustration of the potential for service commissioning in the form of charter 
schools to generate improved returns on public investments in education. However, the case also leads us to note that not all charter schools have been as successful as the Uncommon Schools. While leaders of charter schools including chains of such schools - have often been highly innovative, instances have also been observed of charter schools generating no better outcomes than traditional public schools. The commissioning of education via charter schools has opened the possibility for people like Lemov to enhance the returns we can expect from public investments in education. How could commissioning be set up so that more charter schools produced positive results like the Uncommon Schools? More broadly, how might greater integration of design thinking and community engagement lead to better social outcomes from current and future public policy settings? We believe the increasing focus on the articulation of policy goals at the local level could yield many future benefits. Further systematic empirical work, comparing different ways of commissioning could generate many insights for those seeking better returns on public policy investments.

\section{CONCLUSION}

We have argued that public policies and programs benefit from design thinking. Design thinking increases the likelihood that public policies will become good investments, generating significant positive economic and social outcomes. We reviewed design thinking and public service provision. We then noted how differences in the implementation and management of public services can generate strikingly different local outcomes. From here we made the general argument that effective commissioning can improve the returns from public investments. We used the case of Uncommon Schools - a chain of charter schools operating in the United States - to illustrate how knowledge of local contexts can improve commissioning and, hence, returns from public investments. The case revealed how design thinking can improve commissioning and increase the odds that public investments will generate anticipated social and economic outcomes.

Commissioning should not be viewed as a one-off or periodic practice across the life cycle of public programs. This often happens when governments contract with third parties to provide services - such as schools, health services, or elements of public transport. 'Set and forget' approaches to service provision can arise. Evidence from various policy investment analyses reveals that returns from past investments can often be enhanced through subsequent incremental adjustments in service delivery and governance arrangements (Mintrom 2018). Design thinking holds the promise of improving the analytical capabilities of governance systems. This can be achieved through harnessing knowledge situated in local contexts and analyzing different points of view to effectively address complex situations and needs. In turn, this can support 
better service commissioning. By implication, there is merit in designing public policies in ways that allow for a degree of local innovation and client feedback on service quality and how it could be improved. When policy design is used to encourage innovation, several actions need to be taken. It is important that incentives are given for organizations to innovate. It is also important that impediments to innovation are reduced. Finally, it can be helpful when mechanisms are put in place to monitor innovative programs, collate key insights and make them broadly known.

Governments everywhere will always face pressures to provide more and better services to citizens while keeping taxes as low as possible. Given these dynamics, experiments with the governance and commissioning of service provision should be prioritized. It is an area of public management ripe for further evidence-based investigations of the conditions under which changes can produce sustained, beneficial social and economic outcomes.

The returns on investment in policy and programs could be strengthened through consistent efforts to encourage more engagement between traditional policy developers and local service managers. Commissioning arrangements could be designed, implemented, and governed in ways that promote such engagement. We have suggested that insights from design thinking could support such initiatives. Paying more attention to how policies shape local interactions among service providers and citizens is important to achieving better outcomes. Greater application of design thinking opens the desirable possibility of more policy innovation and improved returns on the investment of public funds. 